\title{
Secretogranin II binds to secretogranin III and forms secretory granules with orexin, neuropeptide $\mathrm{Y}$, and POMC
}

\author{
Kikuko Hotta*, Masahiro Hosaka ${ }^{1, *}$, Atsushi Tanabe and Toshiyuki Takeuchi ${ }^{1}$ \\ Laboratory for Endocrinology and Metabolism, Center for Genomic Medicine, RIKEN, 1-7-22 Suehiro-cho, Tsurumi-ku, Yokohama, Kanagawa 230-0045, Japan \\ ${ }^{1}$ Department of Molecular Medicine, Institute for Molecular and Cellular Regulation, Gunma University, 3-39-15 Showa-machi, Maebashi, Gunma 371-8512, \\ Japan \\ (Correspondence should be addressed to K Hotta; Email: kikuko@src.riken.jp) \\ *(K Hotta and M Hosaka contributed equally to this work)
}

\begin{abstract}
Functional variations in the secretogranin III (SCG3) gene are associated with susceptibility to obesity. SCG3 forms secretory granules with orexin, melanin-concentrating hormone $(\mathrm{MCH})$, neuropeptide $\mathrm{Y}(\mathrm{NPY})$, and POMC in the hypothalamus. In this study, we screened proteins for SCG3-binding activity and identified secretogranin II (SCG2) using a yeast two-hybrid system. Immunoprecipitation revealed that SCG2 interacts with SCG3. In situ hybridization and immunohistochemistry indicated that SCG2 was highly expressed in the lateral hypothalamic area, paraventricular nucleus, and arcuate nucleus of the hypothalamus. Doublelabeling immunohistochemical analysis demonstrated that SCG2 was expressed in orexin-, MCH-, NPY-, and POMC-expressing neurons. SCG2 was also coexpressed with SCG3. Upon introduction into neuroblastoma cells, SCG2 was expressed in the cytosol and formed granule-like
\end{abstract}

structures with SCG3, orexin, NPY, or POMC. SCG3 bound to POMC; however, it did not bind to orexin, $\mathrm{MCH}$, or NPY. By contrast, SCG2 formed aggregates with orexin, $\mathrm{MCH}$, NPY, and POMC. SCG2 may act as a hormone carrier for orexin, MCH, NPY, and POMC by binding with SCG3, which targets proteins to the secretory granules. SCG2 mRNA levels increased along with those of SCG3, orexin, $\mathrm{MCH}$, and NPY after a 24-h fast, suggesting that the SCG2/SCG3 system may respond in an adaptive manner to acute body weight changes. However, this SCG2/SCG3 system appears to be unresponsive to chronic body weight changes, such as diet-induced obesity or obesity in $o b / o b$ mice. We suggest that SCG2, as well as SCG3, may be a potential regulator of food intake based on its capacity to accumulate appetite-related hormones into secretory granules.

Journal of Endocrinology (2009) 202, 111-121

\section{Introduction}

Obesity is a major risk factor for diabetes, dyslipidemia, and hypertension (Kopelman 2000). A combination of these metabolic disorders is defined as the metabolic syndrome (Matsuzawa et al. 1999, Wilson \& Grundy 2003), and comorbidity of these conditions significantly increases the risk of cardiovascular diseases. Both genetic and environmental factors contribute to the development of obesity (Maes et al. 1997, Barsh et al. 2000, Rankinen et al. 2006). Genetic studies on mice have suggested that mutations in several genes such as the leptin, proopiomelanocortin $(P O M C)$, and melanocortin-4 receptor genes are implicated in a monogenic form of inherited obesity (Barsh et al. 2000, Rankinen et al. 2006). However, most cases of obesity are caused by polygenic disorders; moreover, genetic susceptibility may differ among various ethnic groups (Barsh et al. 2000, Rankinen et al. 2006). We have recently reported that single-nucleotide polymorphisms (SNPs) in the secretogranin III (SCG3) and myotubularin-related protein 9 (MTMR9) genes are significantly associated with obesity (Tanabe et al. 2007, Yanagiya et al. 2007).
Many genes expressed in the hypothalamus play important roles in the regulation of food intake and are involved in the monogenic and common forms of obesity. For example, the fat mass and obesity-associated (FTO) gene is highly expressed in the hypothalamus and its expression is regulated by fasting and leptin (Frayling et al. 2007, Gerken et al. 2007). Three groups have reported an association between SNPs in the FTO gene and obesity (Dina et al. 2007, Frayling et al. 2007, Scuteri et al. 2007). Variations in the FTO gene have also been associated with obesity in Japanese subjects (Hotta et al. 2008).

SCG3 is also expressed in the hypothalamus, as well as in many endocrine cells, such as pancreatic $\beta$-cells and pituitary cells (Taupenot et al. 2003, Tanabe et al. 2007). SCG3 belongs to a family of acidic secretory proteins known as granins, which are widely expressed in endocrine and neuronal cells (Taupenot et al. 2003). SCG3 mRNA has been cloned from brain- and pituitary-specific mRNA (Ottiger et al. 1990), and is expressed in the paraventricular nucleus (PVN), lateral hypothalamic area (LHA), and arcuate nucleus (ARC) of the hypothalamus, which are important regions for appetite regulation (Tanabe et al. 2007). SCG3 is coexpressed with 
orexin, melanin-concentrating hormone $(\mathrm{MCH})$, neuropeptide Y (NPY), and POMC in the hypothalamus, and it forms granule-like structures in association with these neuropeptides (Tanabe et al. 2007). Furthermore, SCG3 is known to bind chromogranin A (CGA) and targets it to the secretory granules in pituitary corticotroph cells and pancreatic $\beta$-cells (Taupenot et al. 2003, Hosaka et al. 2005, Han et al. 2008, Takeuchi \& Hosaka 2008). CGA coaggregates several peptide hormones in its core, and the aggregate form is directed to secretory granules by SCG3; thus, SCG3 has been proposed to function as a navigator of the peptide hormone carrier protein CGA to the secretory granules. However, in the hypothalamus, the type of peptide hormone carrier proteins, which SCG3 directs into the secretory granules, is unknown.

In the present study, we investigated the proteins that bind to SCG3 using a yeast two-hybrid system, and we found that secretogranin II (SCG2) was bound to SCG3. SCG2 was coexpressed with SCG3, orexin, and NPY, and it formed granule-like structures with them. We investigated the roles of SCG2 in carrying these appetite-related neuropeptides to the secretory granules.

\section{Materials and Methods}

\section{Cell culture}

The 293 Tet-On cell line (Clontech) was cultured in DMEM (Sigma-Aldrich Corp.) containing 10\% fetal bovine serum (FBS), $100 \mathrm{U} / \mathrm{ml}$ penicillin, $100 \mu \mathrm{g} / \mathrm{ml}$ streptomycin, and $100 \mu \mathrm{g} / \mathrm{ml} \mathrm{G} 418$ disulfate. BE(2)-C neuroblastoma cells were purchased from the American Type Culture Collection (Manassas, VA, USA). The cells were cultured in advanced DMEM (Invitrogen) containing $2 \mathrm{mM}$ glutamine, 5\% FBS, $100 \mathrm{U} / \mathrm{ml}$ penicillin, and $100 \mu \mathrm{g} / \mathrm{ml}$ streptomycin.

\section{Animals}

Male mice (C57BL/6, 8 weeks old) were purchased from CLEA Japan (Tokyo, Japan). After anesthetization with sodium pentobarbital $(100 \mathrm{mg} / \mathrm{kg})$, the mice were perfused with 10\% neutral-buffered formalin. The brains were dissected, fixed with tissue fixative (Genostaff, Tokyo, Japan), embedded in paraffin, and sectioned. The tissue sections $(6 \mu \mathrm{m})$ were dewaxed and used for in situ hybridization and immunohistochemistry.

Seven-week-old male C57BL/6 mice were provided regular laboratory chow (CRF-1; Oriental Yeast Co., Ltd, Tokyo, Japan) for 1 week and then deprived of food (free access to water) for $24 \mathrm{~h}$. Male C57BL/6 mice (6 weeks old) were provided with regular laboratory chow or a high-fat diet (High Fat Diet 32; CLEA Japan Inc.) for 8 weeks. The diet composition, calculated as a percentage of total kilocalories, was as follows: regular laboratory chow (14\% fat, $61 \%$ carbohydrate, and $25 \%$ protein) with $3.59 \mathrm{kcal} / \mathrm{g}$; and high-fat diet (57\% fat, 23\% carbohydrate, and 20\% protein) with $5.08 \mathrm{kcal} / \mathrm{g}$. Male $o b / \mathrm{ob}$ and $+/$ ? mice $(6$ weeks old: Oriental Yeast Co., Ltd) were provided with regular laboratory chow for 1 week. These mice were anesthetized with pentobarbital $(10 \mathrm{mg} / 100 \mathrm{~g}$ of body weight). Plasma samples for leptin were obtained and frozen for later assays. A region bordered dorsally by the thalamus, rostrally by the optic chiasm, and caudally by the mamillary bodies was excised and immediately frozen for RNA preparation. Each experiment was performed at least three times. These protocols were approved by the animal ethics committee of RIKEN.

Screening of proteins for SGC3-binding activity using the yeast two-hybrid assay

The coding sequence of human SCG3 was amplified using reverse transcriptase-PCR (RT-PCR) from human brain RNA (Clontech) with primers containing an additional $\mathrm{N}$-terminal EcoRI restriction site before the start codon and a C-terminal SalI restriction site before the stop codon. The PCR product was cloned between the EcoRI and SalI sites of the pGBKT7 vector (Clontech), which was used as the bait construct; the construct was transformed into Saccharomyces cerevisiae strain AH109. A pretransformed human brain Matchmaker cDNA library cloned into pGADT7-rec was purchased from Clontech. The library host strain Y187 was mated with strain AH109, which contained the bait construct, and was screened for proteins binding to SCG3.

\section{Immunoprecipitation}

The coding sequences of human SCG3 and SCG2 were amplified using RT-PCR from human brain RNA using primers with an additional $\mathrm{N}$-terminal MulI restriction site before the start codon and a C-terminal EcoRV restriction site after the stop codon. The PCR products were cloned between the MulI and EcoRV sites of the pBI vector (Clontech). The coding region of human SCG2 was also amplified with primers that included an N-terminal NotI site before the start codon and a C-terminal SalI site after the stop codon. The PCR product was cloned between the NotI and SalI sites of the pBI-SCG3 plasmid. The pBI-SCG3 and pBI-SCG3-SCG2 constructs were transfected into a previously established HEK293 cell line containing the pTet-On vector (Clontech) using Lipofectamine 2000 reagent (Invitrogen). Protein expression was induced by adding $1 \mu \mathrm{g} / \mathrm{ml}$ doxycycline hydrochloride (ICN Biomedicals, Irvine, CA, USA). After $24 \mathrm{~h}$, the cells were collected and homogenized in $1 \mathrm{ml}$ lysis buffer $(50 \mathrm{mM}$ 2-(N-morpholino)-ethanesulfonic acid (MES)-NaOH, $\mathrm{pH}$ $5 \cdot 5,0 \cdot 5 \% \mathrm{NP}-40,0 \cdot 15 \mathrm{M} \mathrm{NaCl}$, and $10 \mathrm{mM} \mathrm{CaCl}_{2}$ ) containing complete EDTA-free protease inhibitor mixture (Roche Diagnostics). After centrifugation, the supernatant was incubated with $200 \mu \mathrm{g} / \mathrm{ml}$ rabbit polyclonal anti-SCG2 
antibody (Santa Cruz Biotechnology, Santa Cruz, CA, USA) at $4{ }^{\circ} \mathrm{C}$ for $1 \mathrm{~h}$. The samples were incubated with a $50 \%$ slurry of protein G Sepharose 4 Fast Flow (GE Healthcare Bio-Sciences, Ltd, Piscataway, NJ, USA) at $4{ }^{\circ} \mathrm{C}$ for $16 \mathrm{~h}$. The slurry was washed thrice with lysis buffer containing SDS sample buffer, and analyzed by western blotting. The SCG3 protein was detected using goat polyclonal anti-SCG3 antibodies (Santa Cruz Biotechnology).

\section{In situ hybridization for SGC2}

Tissue sections of the mouse brain were hybridized with RNA probes as follows: the cDNA containing the entire coding region of mouse SCG2 was subcloned into pCRII-TOPO (Invitrogen). The plasmid was used to generate sense and antisense RNA probes. RNA was labeled with digoxigenin (DIG)-UTP via in vitro transcription with SP6 or T7 RNA polymerase using a DIG RNA Labeling Kit (SP6/T7; Roche Diagnostics). We performed hybridization with DIG-labeled RNA probes at $50^{\circ} \mathrm{C}$ for $18 \mathrm{~h}$. The bound DIG-labeled RNA probes were visualized by an ELISA with alkaline phosphataseconjugated anti-DIG antibodies, 5-bromo-4-chloro-3indolyl phosphate, and nitroblue tetrazolium salt using a DIG Nucleic Acid Detection Kit (Roche Diagnostics).

\section{Immunohistochemistry}

Tissue sections were incubated at $4{ }^{\circ} \mathrm{C}$ overnight with goat polyclonal anti-SCG2 antibodies (1:200; Santa Cruz Biotechnology) and then with biotinylated anti-goat IgG (Dako, Glostrup, Denmark). After incubation with streptavidin-HRP, the tissue sections were incubated with $3,3^{\prime}$-diaminobenzidine tetrahydrochloride and counterstained with hematoxylin.

Tissue sections of the mouse brain were also incubated at $4{ }^{\circ} \mathrm{C}$ overnight with goat polyclonal anti-SCG2 antibodies (1:200) along with rabbit polyclonal antibodies against SCG3 (1:500; ProteinTech Group, Inc., Chicago, IL, USA), MCH (1:500; Phoenix Pharmaceuticals, Belmont, CA, USA), orexin-B (1:500; Chemicon, Temecula, CA, USA), NPY (1:500; PROGEN Biotechnik, Heidelberg, Germany), or POMC (1:5000; Phoenix Pharmaceuticals). The sections were then washed and incubated at room temperature for $2 \mathrm{~h}$ with the secondary antibodies Alexa Fluor 488 donkey anti-goat IgG (1:2000; Molecular Probes, Eugene, OR, USA) and Alexa Fluor 568 donkey anti-rabbit $\operatorname{IgG}$ (1:2000; Molecular Probes). Double immunofluorescence was detected using an Olympus BX51 microscope.

Expression of SCG2, SCG3, orexin, NPY, POMC, and $\mathrm{MCH}$ in BE(2)-C cells

The coding sequences of human SCG3, prepro-orexin, pro$N P Y, P O M C$, and pro- $M C H$ were amplified using RT-PCR from human brain cDNA with primers containing an additional N-terminal NotI restriction site and the Kozak sequence before the start codon and a C-terminal EcoRI restriction site before or after the stop codon. The PCR products were cloned between the NotI and EcoRI sites of the pcDNA3.1/myc-His(-) vector (Invitrogen). The coding region of human SCG2 was also amplified with primers that included an N-terminal NheI site before or after the start codon and a C-terminal HindIII site after the stop codon. The PCR product was cloned between the NheI and HindIII sites of the pcDNA3.1/myc-His $(-)$ vector. The pcDNA$S C G 2$ vector was transfected into $\mathrm{BE}(2)-\mathrm{C}$ cells along with pcDNA-SCG3, pcDNA-prepro-orexin, pcDNA-pro-NPY, pcDNA-POMC, or pcDNA-pro- $M C H$ vectors with Lipofectamine 2000 reagent. For immunocytochemical detection, the cells were fixed with $4 \%$ paraformaldehyde for $15 \mathrm{~min}$ and then treated with $0 \cdot 5 \%$ Triton X-100. The cells were incubated with goat polyclonal anti-SCG2 antibodies (1:500) along with rabbit polyclonal antibodies against SCG3 (1:500), orexin-B (1:500), NPY (1:500), POMC (1:5000), or MCH $(1: 500)$ in PBS containing $1 \%$ BSA overnight at $4{ }^{\circ} \mathrm{C}$. The cells were washed and incubated with the secondary antibodies Alexa Fluor 488 donkey anti-goat IgG (1:2000) and Alexa Fluor 568 donkey anti-rabbit $\operatorname{IgG}(1: 2000)$ at room temperature for $2 \mathrm{~h}$. The cells were observed with an Olympus FV300 confocal laser-scanning microscope.

\section{Aggregation assay}

Recombinant rat SCG2-(29-620), orexin-(33-130), MCH(22-165), NPY-(30-98), and mouse POMC-(27-235) were cloned into the pGEX-6P-1 vector (Amersham Place), and glutathione S-transferase (GST)-fusion proteins were produced in Escherichia coli strain BL21(DE3) and then purified on glutathione beads. To eliminate the GST fragment from the GST-fusion proteins, GST-fused SCG2(29-620), orexin-(33-130), MCH-(22-165), NPY-(30-98), and POMC-(27-235) proteins were digested with PreScission protease (GE Healthcare Bio-Sciences). Each reaction mixture was centrifuged at $3000 \mathrm{~g}$ for $10 \mathrm{~min}$ to obtain SCG2-(29-620), orexin-(33-130), MCH-(22-165), NPY(30-98), and POMC-(27-235). To examine the selfaggregation properties of orexin-(33-130), $\mathrm{MCH}-(22-165)$, NPY-(30-98), and POMC-(27-235), $0 \cdot 5$ or $1 \mu \mathrm{g} / \mathrm{ml}$ of each fragment was incubated in a solution containing $50 \mathrm{mM}$ MES (pH 5.5), $0 \cdot 1 \mathrm{M} \mathrm{NaCl}$, and $10 \mathrm{mM} \mathrm{CaCl}_{2}$ for $2 \mathrm{~h}$ at $37^{\circ} \mathrm{C}$

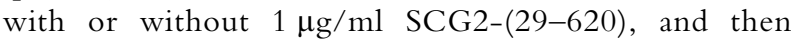
centrifuged at $100000 \mathrm{~g}$ for $30 \mathrm{~min}$ at $4{ }^{\circ} \mathrm{C}$. To prevent non-specific binding of proteins to the polycarbonate ultracentrifuge tubes, $0 \cdot 01 \%$ TritonX-100 was added to the mixture (Song \& Fricker 1995). The pellets (aggregated protein precipitates) and the supernatants of the orexin, $\mathrm{MCH}$, NPY, and POMC protein samples were directly subjected to SDS-PAGE, and the proteins were visualized by immunoblotting using the following antibodies: mouse anti-orexin A monoclonal antibody (R\&D Systems, Inc., Minneapolis, MN, USA); rabbit anti-MCH polyclonal antiserum (Phoenix Pharmaceuticals); rabbit anti-NPY 
polyclonal antiserum (Phoenix Pharmaceuticals); and mouse monoclonal antibody to ACTH (Biogenesis Ltd, Poole, UK). The pellets and the supernatant fraction of the proteins were calculated using the NIH Image software program (http://rsb. info.nih.gov/nih-image/).

\section{Quantitative analysis of $R N A$ expression}

Total RNA was prepared using TRIzol reagent (Invitrogen). The relative amounts of SCG2, SCG3, orexin, MCH, NPY, POMC, and $\beta$-actin mRNA were determined using quantitative real-time PCR. One microgram of total RNA was reverse transcribed using the SuperScript III First-Strand Synthesis System (Invitrogen) according to the manufacturer's instructions. Quantification of the PCR products was performed by measuring the fluorescence from the progressive binding of SYBR Green I dye to double-stranded DNA using the ABI PRISM 7000 Sequence Detection System (Applied Biosystems, Foster City, CA, USA). The quantities of the PCR products were normalized to the level of $\beta$-actin mRNA, which was used as an internal control. We used the following sets of primers: SCG2, 5'-AAGAAGAGCAGCTCGAGCAGGCC- $3^{\prime}$ and $5^{\prime}$-GGTACTGTCTGTTTGGGGTGTCC-3'; SCG3, 5' -CCGGCTCTTGGATACTGGTGTTG- $3^{\prime}$ and $5^{\prime}$-ATCTTGTCTGCCTCTGCCTCAGCG$3^{\prime}$; orexin, $5^{\prime}$-GCCTCCTTCAGGCCAACGGT-AA-3' and $5^{\prime}$-GGGGTGCTAAAGCGGTGGTAGT- ${ }^{\prime} ;$ MCH, $5^{\prime}$-GGAAGGAGAGATTTTGACATGCTC- $3^{\prime}$ and $5^{\prime}$-TTCTTCTGTAAGGATGTTGCGGAC-3'; NPY, 5'-GTTTGGG CATTCTGGCTGAGGG- $3^{\prime}$ and $5^{\prime}$-TGTCTCAGGGCTGGATCTCTTGC-3'; POMC, $5^{\prime}$-ATAGATGTGTGGAGCTGGTGCC- $3^{\prime}$ and $5^{\prime}$-TCATCTCCGTTGCCAGGAAACAC- $3^{\prime}$; and $\beta$-actin, $5^{\prime}$-GAATGGGTCAGAAGGACTCCTATG- $3^{\prime}$ and $5^{\prime}$-CCAGTTGGTAACAATGCCATGT-3'.

\section{Measurement of plasma leptin levels}

The concentration of plasma leptin was determined by ELISA using a mouse leptin ELISA kit (Morinaga Institute of Biological Science, Inc., Yokohama, Japan).

\section{Statistical analysis}

Data are expressed as mean \pm s.D. Differences between the two groups were determined using a Student's $t$-test.

\section{Results}

\section{Identification of proteins binding to SCG3}

We screened proteins that interact with SCG3 using a yeasttwo hybrid system, and we found that SCG2 interacts with SCG3. We performed a $\beta$-galactosidase assay to confirm the binding of SCG2 to SCG3. To further confirm the specific interaction between SCG3 and SCG2, we conducted immunoprecipitation experiments. HEK293 cells were cotransfected with plasmids encoding SCG2 and SCG3, and the cell lysates were incubated with rabbit anti-SCG2 antibodies for immunoprecipitation. The precipitant was analyzed by Western blotting with goat anti-SCG3 antibodies. An immunoreactive band was clearly observed, suggesting that SCG3 interacts with SCG2 in the cell (Fig. 1).

\section{Expression of SCG2 in the hypothalamus and in culture cells}

To confirm that SCG2 is expressed in the hypothalamus, as reported in several studies (Mahata et al. 1992, Ang et al. 1997, Hervé et al. 1998), we performed in situ hybridization and immunohistochemical analysis. Both experiments revealed that SCG2 was intensely expressed in the dorsal LHA to zona incerta, PVN, and ARC. SCG2 was also expressed in the ventromedial nucleus and amygdaloid nucleus (Fig. 2 and the electronic supplementary data, see Supplementary data in the online version of the Journal of Endocrinology at http:// joe.endocrinology-journals.org/content/vol202/issue1/). We then investigated the relationship between SCG2 and appetite-related peptides by double-labeling immunohistochemical analysis, and we found that SCG2 was coexpressed with POMC and NPY in ARC cells (Fig. 3). Next, we examined the relationship between SCG2 and two major neuropeptides, orexin and $\mathrm{MCH}$, in the LHA. We found that many orexin-expressing neurons also expressed SCG2; however, $\mathrm{MCH}$-expressing neurons exhibited a very low level of SCG2 (Fig. 3). SCG2-expressing neurons also expressed SCG3, which is coexpressed with NPY, POMC, orexin, and MCH (Tanabe et al. 2007; Fig. 3).

SCG3 reportedly forms granule-like structures and colocalizes with orexin, MCH, NPY, and POMC when they are coexpressed in culture cells (Tanabe et al. 2007).

\begin{tabular}{|l|r|c|c|c|c|}
\hline \multirow{2}{*}{ Vector } & SCG3 & + & + & + & + \\
\cline { 2 - 6 } & SCG2 & + & - & + & - \\
\hline Anti-SCG2 antibody & + & + & - & - \\
\hline $75 \mathrm{kD}-$ \\
$50 \mathrm{kD} —$
\end{tabular}

Figure 1 Coimmunoprecipitation of SCG2 with SCG3. The $\mathrm{pBI}-\mathrm{SCG} 3$ or $\mathrm{pBI}-\mathrm{SCG} 3-\mathrm{SCG} 2$ vector was transfected into HEK293 cells containing the pTet-On vector. Protein expression was induced by adding $1 \mu \mathrm{g} / \mathrm{ml}$ doxycycline hydrochloride. After $24 \mathrm{~h}$, the cells were collected and homogenized in $1 \mathrm{ml}$ lysis buffer containing protease inhibitors. After centrifugation, the supernatant was incubated with $200 \mu \mathrm{g} / \mathrm{ml}$ rabbit polyclonal anti-SCG2 antibodies at $4{ }^{\circ} \mathrm{C}$ for $1 \mathrm{~h}$. The samples were incubated with a $50 \%$ slurry of protein G Sepharose 4 Fast Flow at $4{ }^{\circ} \mathrm{C}$ for $16 \mathrm{~h}$. The slurry was washed with the lysis buffer and was analyzed by western blotting. The SCG3 protein was detected using goat polyclonal anti-SCG3 antibody. 
A
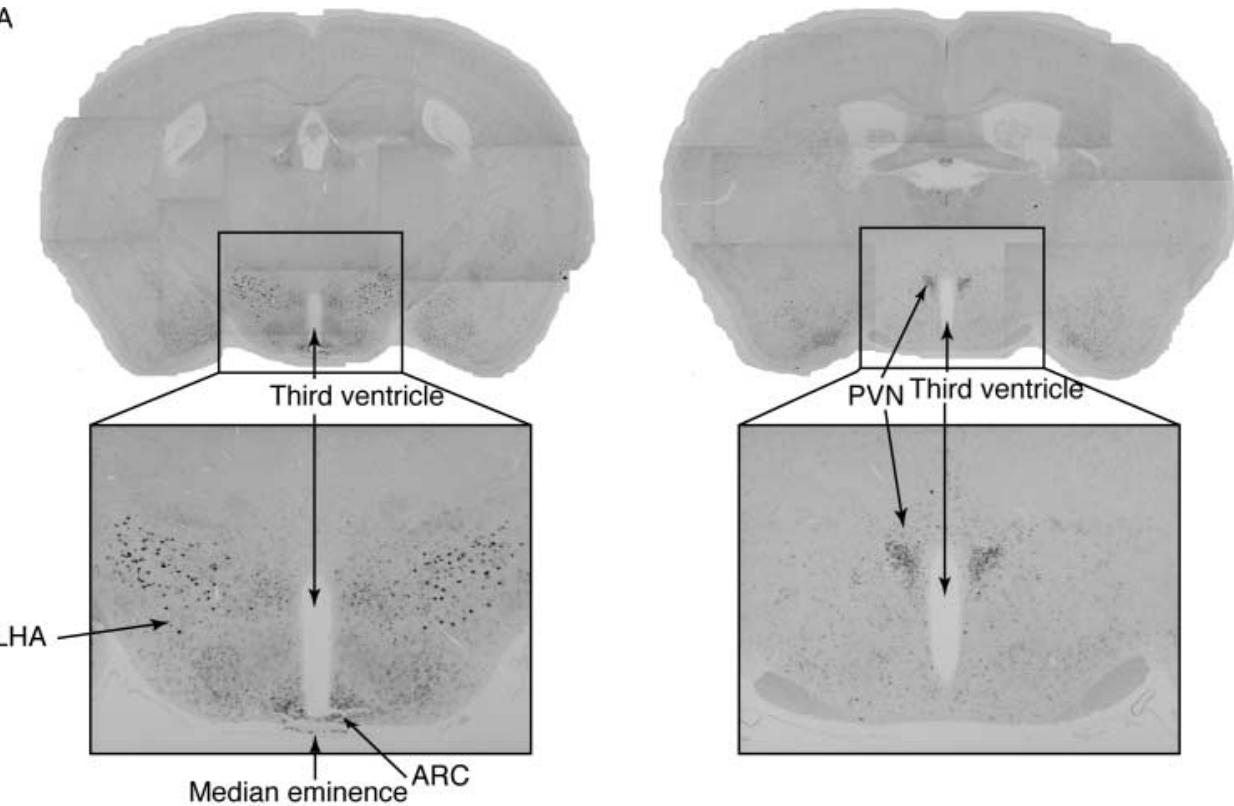

B
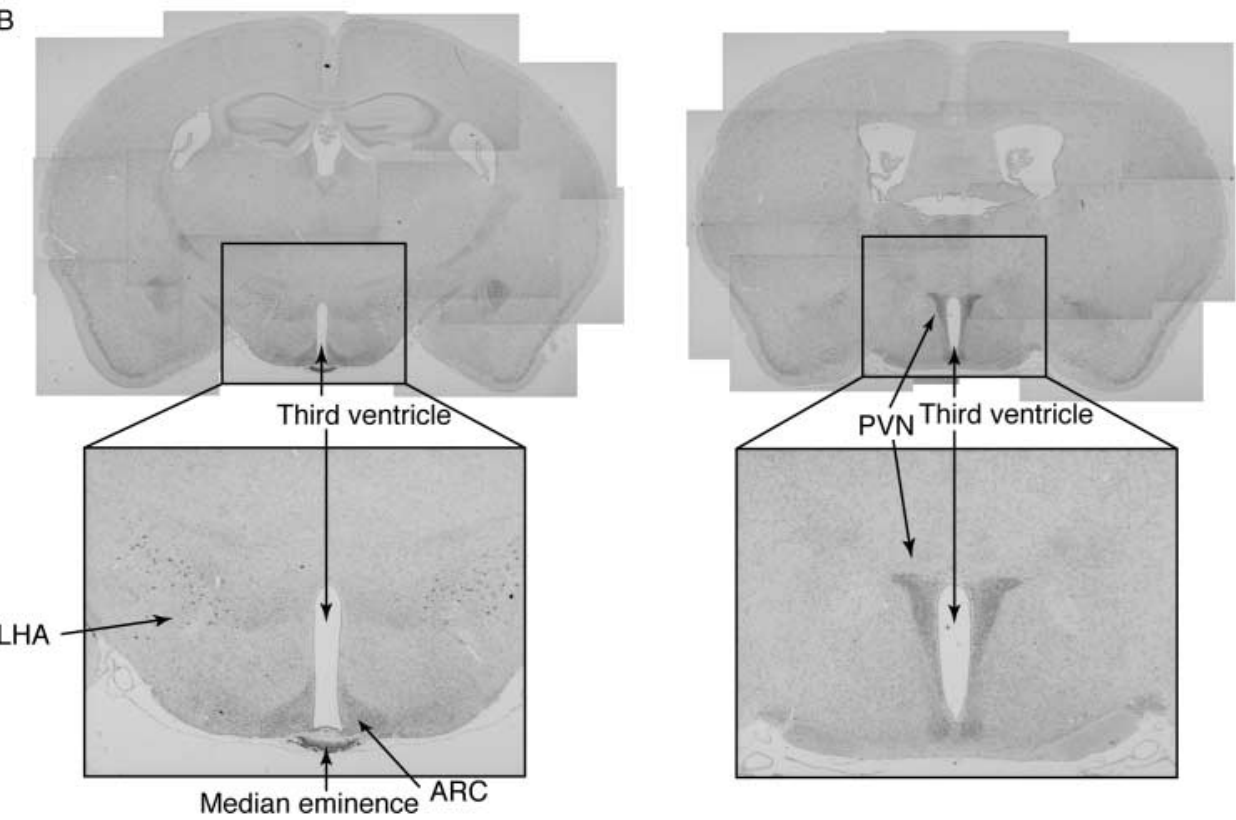

Figure 2 (A) In situ hybridization and (B) immunohistochemistry of SCG2 in the mouse brain. (A) Tissue sections were hybridized with a DIG-labeled RNA probe for SCG2. The bound DIG-labeled RNA probes were visualized by ELISA with alkaline phosphatase-conjugated anti-DIG antibodies, 5-bromo-4-chloro-3indolyl phosphate (BCIP), and nitroblue tetrazolium salt (NBT). (B) Tissue sections were incubated with goat polyclonal anti-SCG2 antibody and then with biotinylated anti-goat IgG. After incubation with streptavidin-HRP, the tissue sections were further incubated with 3,3'-diaminobenzidine tetrahydrochloride $(\mathrm{DAB})$ and counterstained with hematoxylin.

To further investigate whether SCG2 also forms granule-like structures, we cotransfected $\mathrm{BE}(2)-\mathrm{C}$ cells with plasmids expressing SCG2 and with those expressing prepro-orexin, POMC, pro-NPY, pro-MCH, or SCG3. It was found that SCG2 formed granule-like structures, as previously reported (Beuret et al. 2004), and clearly colocalized with SCG3, orexin, NPY, POMC, and MCH (Fig. 4). To further confirm the colocalization, we constructed vectors expressing the following fusion proteins: SCG2-V5; SCG3-myc; prepro-orexin-myc; POMC-myc; pro-NPY-myc; and pro-MCH-myc. Similar results were obtained when cells were transfected with these vectors and stained with anti-myc 
LHA

SCG2
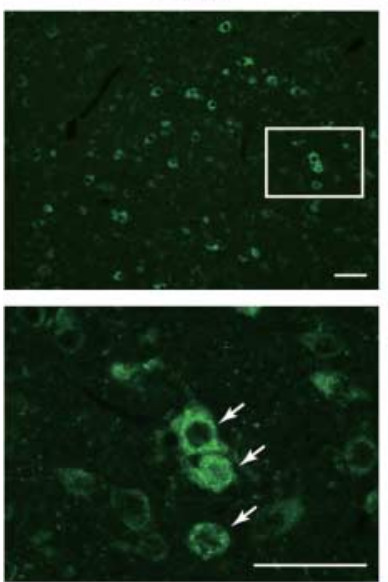

SCG2
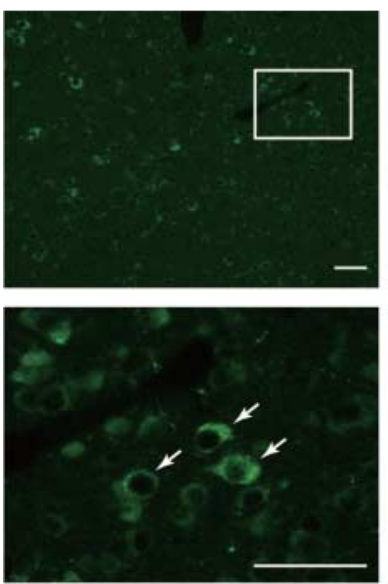

SCG2
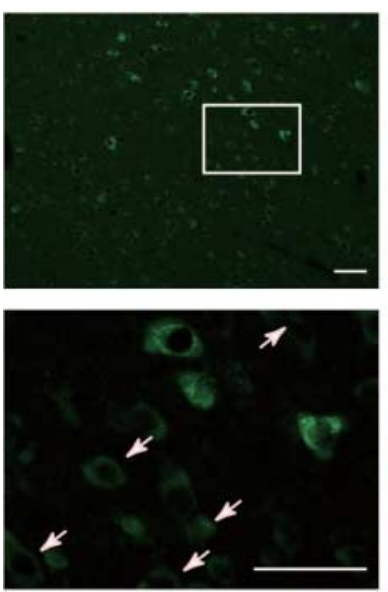

SCG3
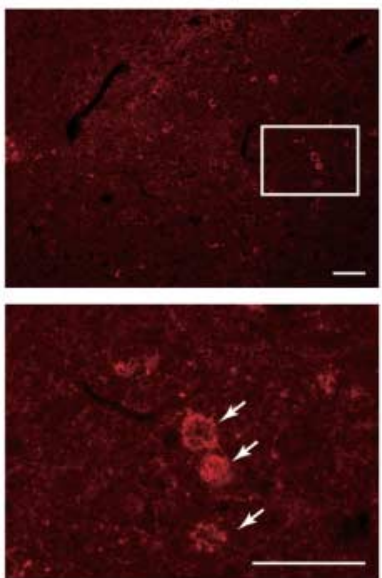

Orexin B
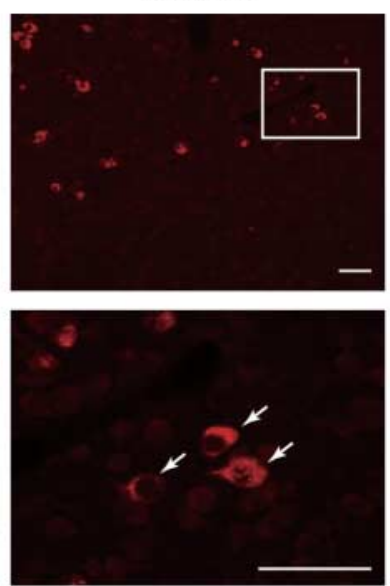

$\mathrm{MCH}$
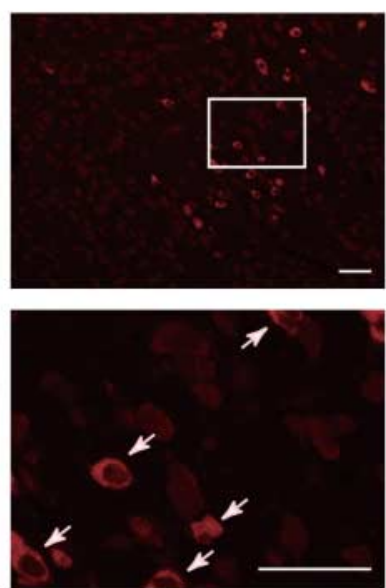

ARC

SCG2
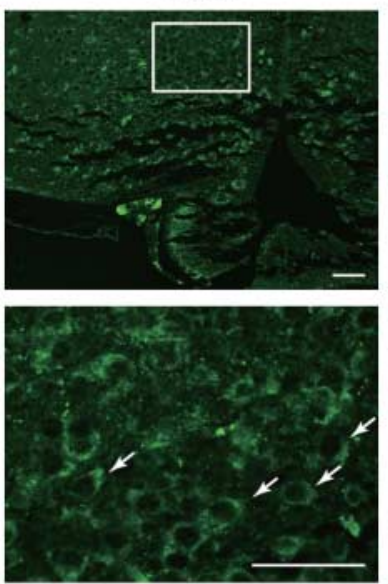

SCG2
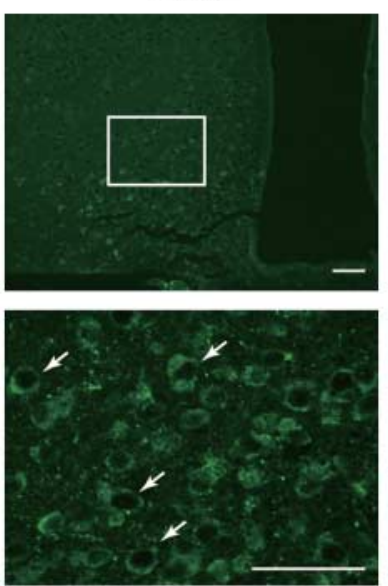

SCG2
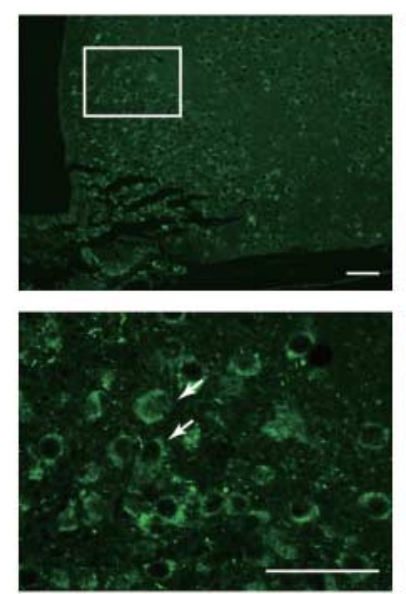

SCG3
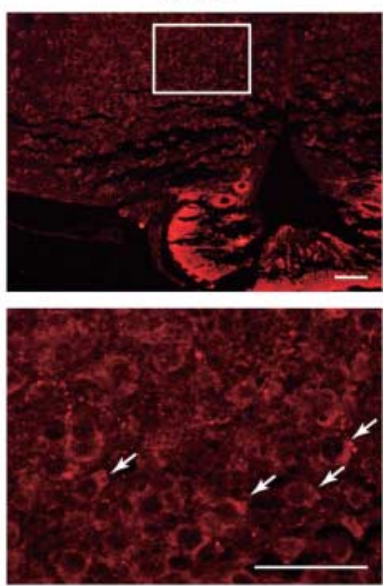

NPY
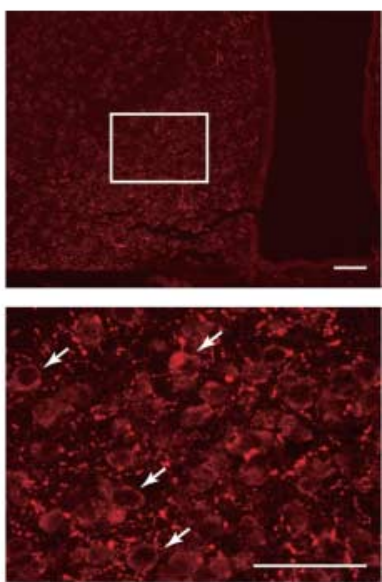

POMC
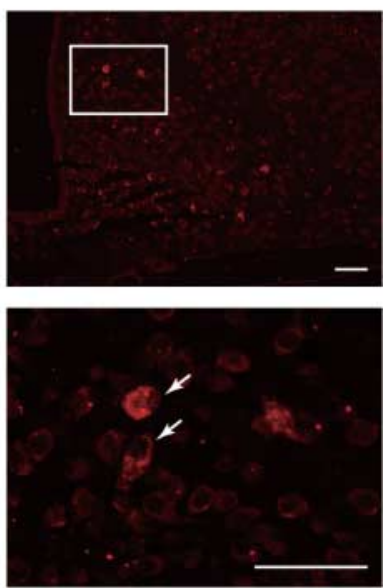

Figure 3 Colocalization of SCG2 with SCG3, NPY, POMC, orexin, and MCH in the mouse hypothalamus. Tissue sections were double immunostained for SCG2 and SCG3, POMC, NPY, MCH, or orexin B. The images in the lower panel are enlarged versions of the

corresponding images in the upper panel. SCG3-, NPY-, POMC-, orexin-, and MCH-expressing neurons with SCG2 expression are indicated by arrows. Scale bar, $50 \mu \mathrm{m}$. 


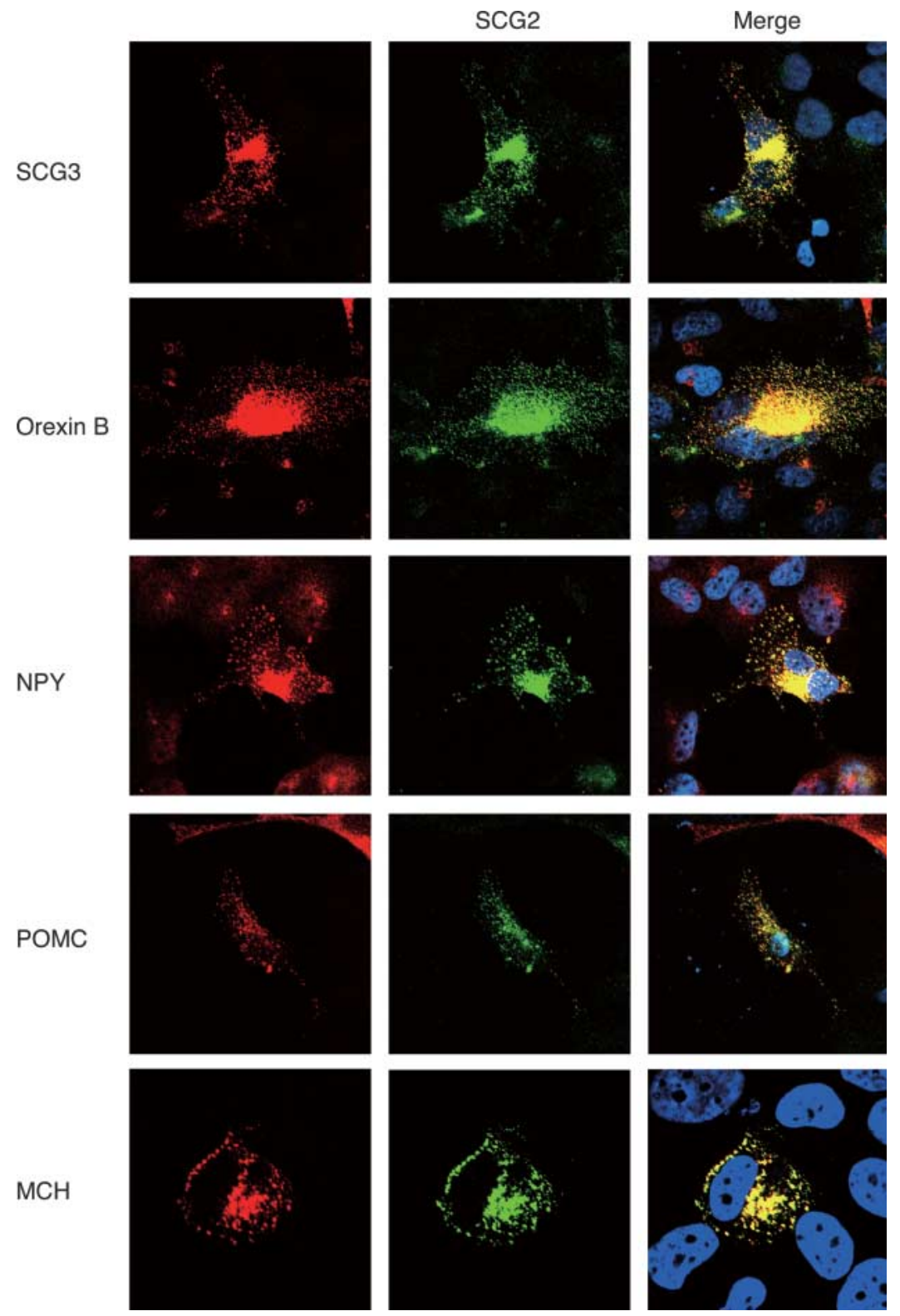

Figure 4 Cellular localization of the SCG2 protein that was overexpressed in the BE(2)-C cells. BE(2)-C cells expressed SCG2 (green stain) along with SCG3 (red stain), orexin (red stain), POMC (red stain), NPY (red stain), or MCH (red stain).

and anti-V5 antibodies (data not shown). More than $90 \%$ of the cells transfected with the two plasmids showed overlapping immunocytochemical staining.

\section{Aggregation assay}

Because CGA has been reported to form a self-aggregate and a coaggregate with adrenomedulin in adrenochromaffin cells (Han et al. 2008), we performed an assay to examine whether SCG2 forms a self-aggregate and coaggregate with orexin, MCH, NPY, and POMC. For this purpose, we prepared recombinant rat SCG2-(29-620), orexin-(33-130), MCH-(22-165), NPY-(30-98), and mouse POMC-(27-235). Self-aggregation was observed in orexin-(33-130), MCH-(22-165), NPY-(30-98), and POMC-(27-235), and coaggregation with SGC2 was enhanced by increasing the amounts of SCG2 (Fig. 5). The interaction of SCG2 with orexin, MCH, NPY, and POMC was also confirmed using the yeast two-hybrid assay. By contrast, the assay and immunoprecipitation results showed that SCG3 interacted with POMC, but not with orexin, MCH, or NPY. 
A
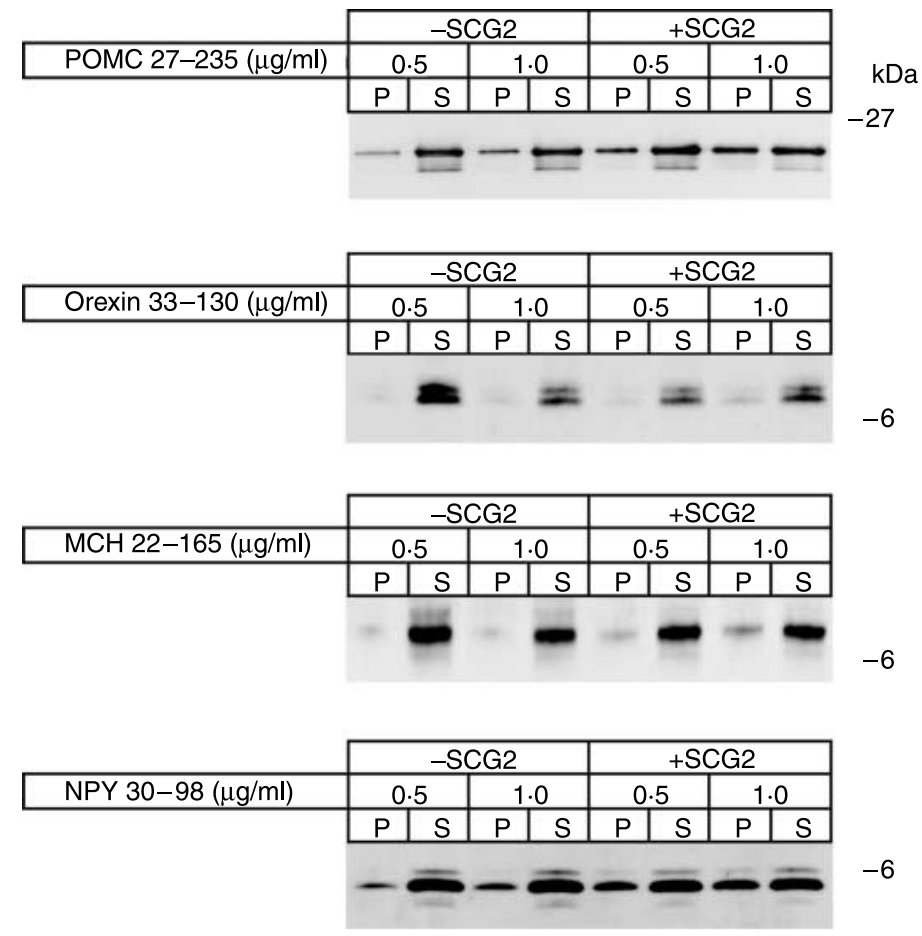

B

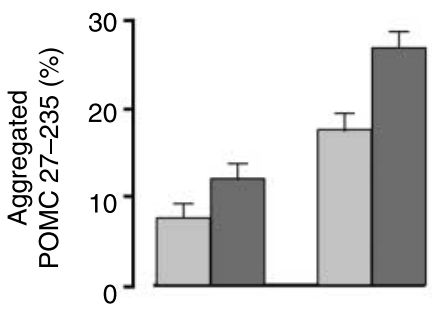

POMC 27-235 conc. $(\mu \mathrm{g} / \mathrm{ml})$

SCG2 $(1.0 \mu \mathrm{g} / \mathrm{ml})$
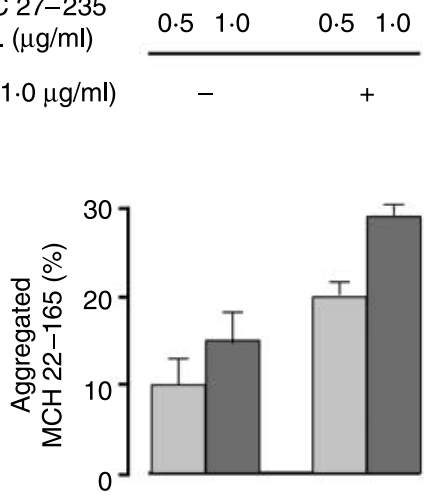

$\mathrm{MCH} 22-165$

conc. $(\mu \mathrm{g} / \mathrm{ml})$

SCG2 $(1.0 \mu \mathrm{g} / \mathrm{ml})$

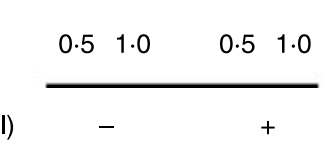

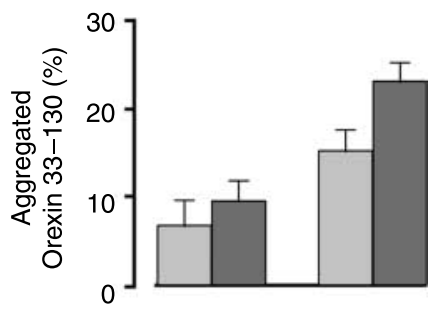

Orexin 33-130 conc. $(\mu \mathrm{g} / \mathrm{ml})$

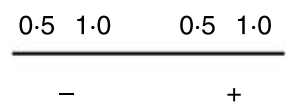

$\operatorname{SCG2}(1.0 \mu \mathrm{g} / \mathrm{ml}) \quad$ - $\quad$ +

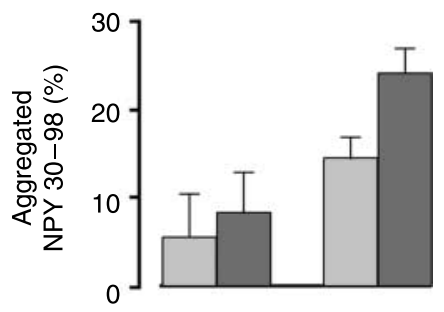

NPY $30-98$ conc. $(\mu \mathrm{g} / \mathrm{ml})$

$0.5 \quad 1.0$

$0.5 \quad 1.0$

SCG2 $(1.0 \mu \mathrm{g} / \mathrm{ml})$

Figure 5 Coaggregation of peptide hormone precursors with SCG2. Orexin, MCH, NPY, or POMC was incubated with or without $1 \mu \mathrm{g} / \mathrm{ml}$ SCG2 at the indicated concentration in an intragranular milieu at $\mathrm{pH} 5.5$ and $10 \mathrm{mM} \mathrm{Ca}^{2+}$. The samples were centrifuged and the pellets ( $\mathrm{P}$, precipitates of aggregated proteins) and supernatants $(\mathrm{S})$ were directly subjected to SDS-PAGE $(\mathrm{A})$. The amounts of protein in the pellet and supernatant fractions were calculated using the NIH Image software program (B). The coaggregate formation of orexin, MCH, NPY, or POMC with SCG2 was expressed as the ratio of protein amount in the pellet fraction to that in the supernatant fraction plus that in the pellet fraction. 
Regulation of SCG2 expression in the hypothalamus

To examine the regulatory mechanism of SCG2 in the murine hypothalamus, we examined the effects of fasting, a high-fat diet, and leptin deficiency on SCG2 expression. When mice were fasted for $24 \mathrm{~h}$, their body weight and plasma leptin levels significantly decreased; the mean body weight and plasma leptin of the control mice were $21 \cdot 0 \pm 0.6 \mathrm{~g}$ and $5 \cdot 8 \pm 2.6 \mathrm{ng} / \mathrm{ml}$ respectively, and those of
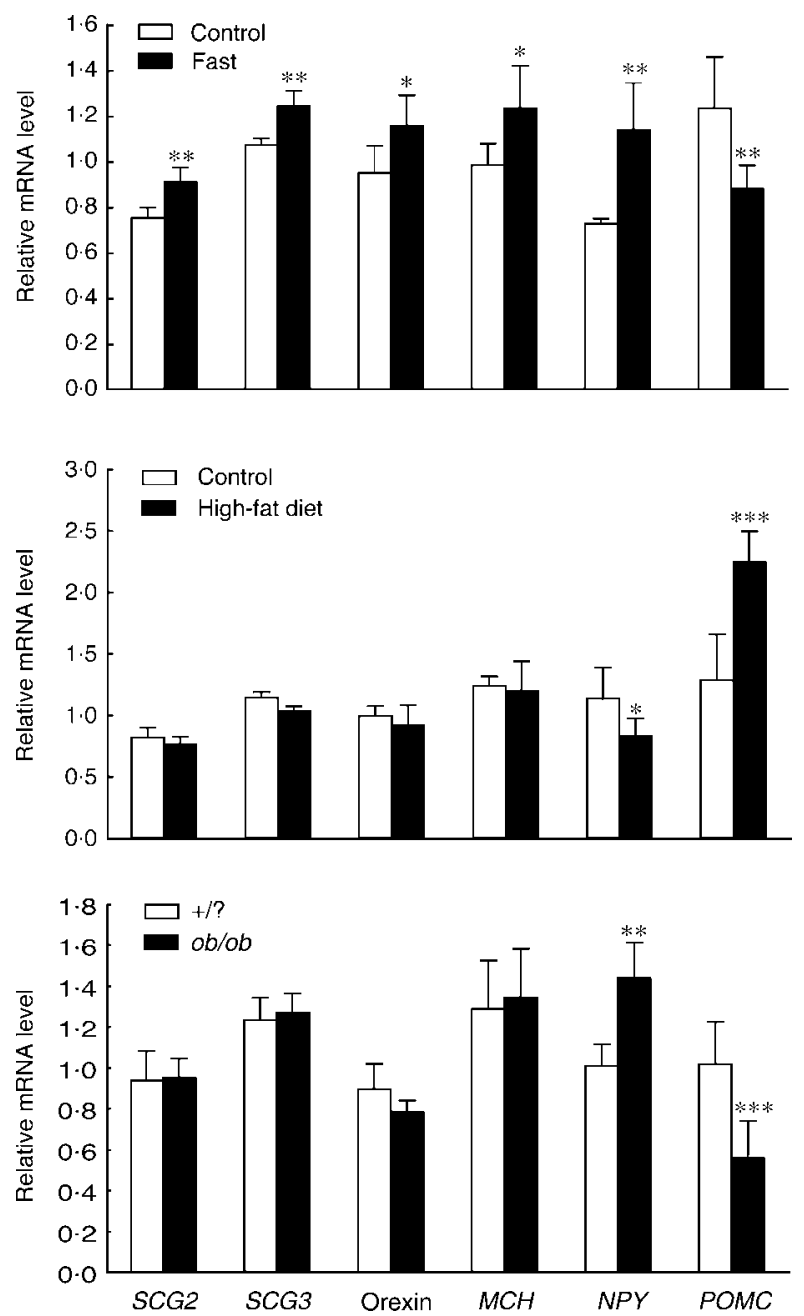

Figure 6 Effects of fasting, a high-fat diet, and leptin deficiency on the mRNA expressions of SCG2, SCG3, orexin, $M C H, N P Y$, and POMC. Upper panel: 7 -week-old mice $(n=6)$ were deprived of food (free access to water) for $24 \mathrm{~h}$ after being provided with regular laboratory chow for 1 week. Middle panel: mice ( 7 weeks old) were provided with regular laboratory chow $(n=6)$ or with a high-fat diet $(n=6)$ for 8 weeks. Lower panel: 7 -week-old $o b / o b$ and $+/$ ? mice were provided with regular laboratory chow for 1 week and the hypothalamic region was obtained. Relative amounts of SCG2, $S C G 3$, orexin, $M C H, N P Y, P O M C$, and $\beta$-actin mRNA were determined by quantitative real-time PCR. The quantities were normalized to the mRNA level of $\beta$-actin, which was used as an internal control. Data are expressed as mean \pm s.D. ${ }^{*} P<0 \cdot 05$; ${ }^{* *} P<0 \cdot 01$; ${ }^{* * *} P<0 \cdot 001$ (Student's $t$-test). fasted mice were $17 \cdot 3 \pm 0 \cdot 3 \mathrm{~g}(P<0 \cdot 0001)$ and $2 \cdot 5 \pm 1 \cdot 2 \mathrm{ng} / \mathrm{ml}$ $(P<0 \cdot 05)$ respectively. As shown in Fig. 6, the mRNA levels of both SCG2 and SCG3 increased after a 24-h fast. Similarly, the mRNA levels of the orexigenic peptides orexin, $\mathrm{MCH}$, and NPY also increased after a 24-h fast. By contrast, the POMC mRNA level decreased because of fasting. We repeated these experiments three times and obtained similar results; the mRNA levels of SCG 2 in the control and fasted mice were respectively $0 \cdot 68 \pm 0.02$ and $0.89 \pm 0.01(P<0 \cdot 05)$ in the second experiment and $0 \cdot 82 \pm 0 \cdot 01$ and $0 \cdot 94 \pm 0 \cdot 01$ $(P<0 \cdot 01)$ in the third experiment. The mRNA levels of SCG3 in the control and fasted mice were respectively $0.72 \pm 0.01$ and $0.92 \pm 0.01 \quad(P<0.01)$ in the second experiment and $0.93 \pm 0.01$ and $1.03 \pm 0.01(P<0.01)$ in the third experiment. In situ hybridization indicated that SCG2 and SCG3 mRNA levels increased in the PVN and LHA after a 24-h fast. The mRNA levels in the ARC slightly increased (Fig. 7).

When mice were fed with a high-fat diet for 8 weeks, their body weights markedly increased; the mean body weight and plasma leptin level of the control mice were $27 \cdot 0 \pm 3 \cdot 2 \mathrm{~g}$ and $5.9 \pm 2.5 \mathrm{ng} / \mathrm{ml}$ respectively, and those of mice fed with a high-fat diet were $33.4 \pm 2.5 \mathrm{~g} \quad(P<0.001)$ and $47.9 \pm 18.0 \mathrm{ng} / \mathrm{ml}(P<0.0001)$ respectively. However, the mRNA levels of SCG2, SCG3, orexin, and $\mathrm{MCH}$ remained unaltered. In the other two experiments, no significant changes were observed in the mRNA levels of SCG2 and SCG3 when the high-fat diet was used. By contrast, the mRNA level of the orexigenic peptide NPY significantly decreased, whereas that of the anorectic peptide POMC significantly increased with a high-fat diet. Next, we examined the expression of these mRNAs in the $o b / o b$ (leptin deficient; body weight, $46 \cdot 7 \pm 2 \cdot 8 \mathrm{~g}$; plasma leptin, not detected) and $+/$ ? (control; body weight, $24 \cdot 6 \pm 1 \cdot 1 \mathrm{~g}$; plasma leptin, $3 \cdot 5 \pm 1 \cdot 2 \mathrm{ng} / \mathrm{ml}$ ) mice. We observed that the mRNA levels of SCG2, SCG3, orexin, and $\mathrm{MCH}$ were unaltered between the $o b / o b$ and $+/$ ? mice, as seen in the experiment in which the mice were fed with a high-fat diet. In the other two experiments, no significant changes were observed in the mRNA levels of SCG2 and SCG3 between $o b / o b$ and $+/$ ? mice. By contrast, the NPY mRNA level was significantly higher, whereas the POMC mRNA level was significantly lower in the ob/ob mice (Fig. 6).

\section{Discussion}

We found that SCG2 binds to SCG3, which based on SNP analysis, have an association with obesity (Tanabe et al. 2007). SCG2 was highly expressed in the hypothalamic nuclei, PVN, LHA, ARC, and amygdaloid nucleus, which are known to form the main centre of appetite regulation (Schwartz et al. 2000). Thus, we considered that SCG2 might play an important role in the regulation of food intake. The present study found that SCG2, together with SCG3, was expressed in the orexin-, NPY-, and POMC-expressing neurons. SCG2 

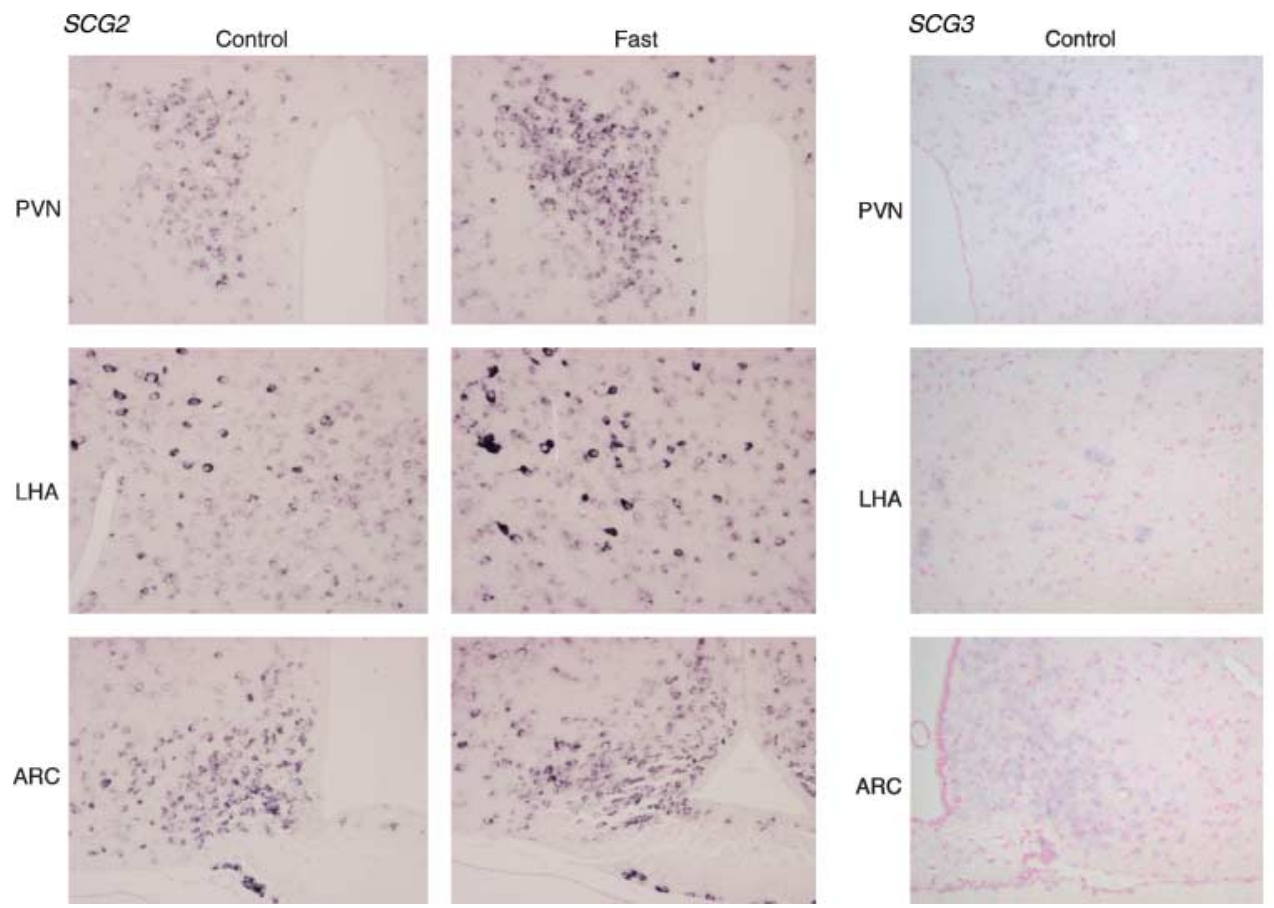

Figure 7 Effect of fasting on the mRNA expression of SCG2 and SCG3 in PVN, LHA, and ARC. Seven-week-old mice ( $n=6)$ were deprived of food (free access to water) for $24 \mathrm{~h}$ after being provided with regular laboratory chow for 1 week. Tissue sections were hybridized with a DIG-labeled RNA probe for SCG2 and SCG3. The bound DIG-labeled RNA probes were visualized by ELISA with alkaline phosphataseconjugated anti-DIG antibodies, 5-bromo-4-chloro-3-indolyl phosphate (BCIP), and nitroblue tetrazolium salt (NBT).

and SCG3 were expressed as a granule-like structure in the cell, and they were colocalized with orexin, NPY, MCH, and POMC. In this study, we demonstrated that SCG2 and SCG3 form a secretory granule core complex with these peptides. As previously reported (Hosaka et al. 2005, Takeuchi \& Hosaka 2008), SCG3 bound to POMC; however, it did not bind to orexin, MCH, or NPY. By contrast, SCG2 formed aggregates with orexin, MCH, NPY, and POMC. Because SCG3 acts as a sorting receptor that directs hormone carrier proteins to the secretory granules, SCG2 may act as a hormone carrier for orexin, MCH, NPY, and POMC to SCG3.

The expression of SCG2 in MCH neuron was much lower than that in orexin, NPY, or POMC neurons. Although further investigation is required, the distinct granin composition of secretory granules may determine $\mathrm{MCH}$-specific secretory and release mechanisms different from those for orexin and NPY.

The mRNA levels of SCG2, SCG3, orexin, MCH, and NPY increased in the hypothalamus of mice after a 24-h fast. By contrast, the mRNA levels of these proteins and peptide hormones were unchanged between mice fed with a high-fat diet and those fed with a normal chow diet. Similarly, these mRNA levels were also unaltered between leptin-deficient mice (ob/ob mice) and lean control mice. Therefore, the mRNA levels of SCG2, SCG3, orexin, and MCH may be regulated during an acute body weight loss, but not during chronic body weight gain. Because the leptin level was decreased by fasting and increased by a high-fat diet, these mRNA levels may be regulated by a sharp decrease in the leptin level. By contrast, they were not regulated by a gradual increase in the leptin level or continuous leptin deficiency. Leptin is postulated to play an important role in the regulation of energy deficit rather than energy excess (i.e. obesity; Chan \& Mantzoros 2005). Therefore, SCG2 and SCG3, along with orexin and $\mathrm{MCH}$, would play more essential roles during an energy deficit than during an energy excess. By contrast, the NPY and POMC mRNA levels appeared to be regulated by leptin levels, but not by mechanisms involving SCG2 and SCG3 mRNAs. The NPY and POMC neurons exist in the ARC, adjacent to the third ventricle, and are the first-order neurons in the hypothalamic response to circulating leptin. The first-order NPY and POMC neurons are regulated by leptin, and are projected to the PVN and the LHA, where the second-order hypothalamic neuropeptide neurons (such as orexin and $\mathrm{MCH}$ neurons) act to regulate food intake and energy homeostasis (Schwartz et al. 2000). This signaling system would also affect the SCG2 and SCG3 mRNA levels, since these mRNA levels increased more substantially in the LHA and PVN compared with the ARC after fasting, although the comparison was qualitative rather than quantitative.

In conclusion, we identified SCG2 as an SCG3-binding protein. To our knowledge, there are no reports indicating the involvement of SCG2 in appetite regulation; however, 
in view of the present data, we propose that SCG2 is a potential regulator of food intake, because SCG2, together with SCG3, forms a secretory granule core complex with orexin, NPY, POMC, and MCH.

\section{Declaration of interest}

The authors of this manuscript have nothing to declare.

\section{Funding}

This work was supported by the Japanese Millennium Project and the Takeda Science Foundation.

\section{Author contribution statement}

$\mathrm{K} \mathrm{H}, \mathrm{M} \mathrm{H}$, and A T performed the experiments. $\mathrm{K} \mathrm{H}$ and $\mathrm{T} \mathrm{T}$ prepared the manuscript. K H was responsible for the design of the study. All authors read and approved the final manuscript.

\section{Acknowledgements}

We are grateful to Ms Kaoru Nakene and Ms Ritsuko Kusano for their contribution to our study.

\section{References}

Ang CW, Dotman CH, Winkler H, Fischer-Colbrie R, Sonnemans MA \& Van Leeuwen FW 1997 Specific expression of secretogranin II in magnocellular vasopressin neurons of the rat supraoptic and paraventricular nucleus in response to osmotic stimulation. Brain Research 765 13-20.

Barsh GS, Farooqi IS \& O'Rahilly S 2000 Genetics of body-weight regulation. Nature 404 644-651.

Beuret N, Stettler H, Renold A, Rutishauser J \& Spiess M 2004 Expression of regulated secretory proteins is sufficient to generate granule-like structures in constitutively secreting cells. Journal of Biological Chemistry 279 20242-20249.

Chan JL \& Mantzoros CS 2005 Role of leptin in energy-deprivation states: normal human physiology and clinical implications for hypothalamic amenorrhoea and anorexia nervosa. Lancet 366 74-85.

Dina C, Meyre D, Gallina S, Durand E, Körner A, Jacobson P, Carlsson LM, Kiess W, Vatin V, Lecoeur C et al. 2007 Variation in FTO contributes to childhood obesity and severe adult obesity. Nature Genetics 39 724-726.

Frayling TM, Timpson NJ, Weedon MN, Zeggini E, Freathy RM, Lindgren CM, Perry JR, Elliott KS, Lango H, Rayner NW et al. 2007 A common variant in the FTO gene is associated with body mass index and predisposes to childhood and adult obesity. Science 316 889-894.

Gerken T, Girard CA, Tung YC, Webby CJ, Saudek V, Hewitson KS, Yeo GS, McDonough MA, Cunliffe S, McNeill LA et al. 2007 The obesityassociated FTO gene encodes a 2-oxoglutarate-dependent nucleic acid demethylase. Science 318 1469-1472.

Han L, Suda M, Tsuzuki K, Wang R, Ohe T, Hirai H, Watanabe T, Takeuchi T \& Hosaka M 2008 A large form of secretogranin III functions as a sorting receptor for chromogranin A aggregates in PC12 cells. Molecular Endocrinology 22 1935-1949.
Hervé C, Colard C, Grillon S, Fellmann D \& Griffond B 1998 Polyethylene glycol-induced hypovolemia affects the expression of MCH mRNA, but not dynorphin or secretogranin II mRNAs, in the rat lateral hypothalamus. Neuroscience Letters 248 133-137.

Hosaka M, Watanabe T, Sakai Y, Kato T \& Takeuchi T 2005 Interaction between secretogranin III and carboxypeptidase E facilitates prohormone sorting within secretory granules. Journal of Cell Science 118 4785-4795.

Hotta K, Nakata Y, Matsuo T, Kamohara S, Kotani K, Komatsu R, Itoh N, Mineo I, Wada J, Masuzaki H et al. 2008 Variations in the FTO gene are associated with severe obesity in the Japanese. Journal of Human Genetics $\mathbf{5 3}$ 546-553.

Kopelman PG 2000 Obesity as a medical problem. Nature 404 635-643.

Maes HH, Neale MC \& Eaves LJ 1997 Genetic and environmental factors in relative body weight and human adiposity. Behavior Genetics 27 325-351.

Mahata SK, Mahata M, Steiner HJ, Fischer-Colbrie R \& Winkler H 1992 In situ hybridization: mRNA levels of secretogranin II, neuropeptides and carboxypeptidase $\mathrm{H}$ in brains of salt-loaded and Brattleboro rats. Neuroscience 48 669-680.

Matsuzawa Y, Funahashi T \& Nakamura T 1999 Molecular mechanism of metabolic syndrome $\mathrm{X}$ : contribution of adipocytokines adipocyte-derived bioactive substances. Annals of the New York Academy of Sciences $\mathbf{8 9 2}$ 146-154.

Ottiger HP, Battenberg EF, Tsou AP, Bloom FE \& Sutcliffe JG 1990 1B1075: a brain- and pituitary-specific mRNA that encodes a novel chromogra$\mathrm{nin} /$ secretogranin-like component of intracellular vesicles. Journal of Neuroscience 10 3135-3147.

Rankinen T, Zuberi A, Chagnon YC, Weisnagel SJ, Argyropoulos G, Walts B, Pérusse L \& Bouchard C 2006 The human obesity gene map: the 2005 update. Obesity 14 529-644.

Schwartz MW, Woods SC, Porte D Jr, Seeley RJ \& Baskin DG 2000 Central nervous system control of food intake. Nature 404 661-671.

Scuteri A, Sanna S, Chen WM, Uda M, Albai G, Strait J, Najjar S, Nagaraja R, Orrú M, Usala G et al. 2007 Genome-wide association scan shows genetic variants in the FTO gene are associated with obesity-related traits. PLoS Genetics 3 1200-1210.

Song L \& Fricker LD 1995 Calcium- and pH-dependent aggregation of carboxypeptidase E. Journal of Biological Chemistry 270 7963-7967.

Takeuchi T \& Hosaka M 2008 Sorting mechanism of peptide hormones and biogenesis mechanism of secretory granules by secretogranin III, a cholesterol-binding protein, in endocrine cells. Current Diabetes Reviews $\mathbf{4}$ 31-38.

Tanabe A, Yanagiya T, Iida A, Saito S, Sekine A, Takahashi A, Nakamura T, Tsunoda T, Kamohara S, Nakata Y et al. 2007 Functional single-nucleotide polymorphisms in the secretogranin III (SCG3) gene that form secretory granules with appetite-related neuropeptides are associated with obesity. Journal of Clinical Endocrinology and Metabolism 92 1145-1154.

Taupenot L, Harper KL \& O'Connor DT 2003 The chromograninsecretogranin family. New England Journal of Medicine 348 1134-1149.

Wilson PW \& Grundy SM 2003 The metabolic syndrome: a practical guide to origins and treatment: part I. Circulation 108 1422-1424.

Yanagiya T, Tanabe A, Iida A, Saito S, Sekine A, Takahashi A, Tsunoda T, Kamohara S, Nakata Y, Kotani K et al. 2007 Association of single-nucleotide polymorphisms in MTMR9 gene with obesity. Human Molecular Genetics 16 3017-3026.

Received in final form 5 April 2009

Accepted 8 April 2009

Made available online as an Accepted Preprint 8 April 2009 